\title{
An investigation of bamboo-strip constructions built according to Yona Friedman's manuals
}

Paolo Chiacchiera MSC

Alumnus, Politecnico di Torino, Turin, Italy

Andrea Bocco MSC, PhD

Professor, Dipartimento Interateneo di Scienze, Progetto e Politiche del Territorio, Politecnico di Torino, Turin, Italy (corresponding author: andrea.bocco@polito.it) (Orcid:0000-0001-5639-5660)

\author{
Walter Ceretto MSC \\ Professor, Dipartimento di Ingegneria Strutturale, Edile e Geotecnica, \\ Politecnico di Torino, Turin, Italy \\ Davide Ghirardotti MSC \\ Alumnus, Politecnico di Torino, Turin, Italy
}

This paper describes a research study on the structural and constructional properties of bamboo strips used in accordance with manuals to improve the quality of self-building authored by Yona Friedman. To investigate these properties, four full-scale roof structures of different designs were built and tested to find their maximum load, deformation behaviour and failure. Two of these structures were subsequently rebuilt to explore strengthening possibilities that were assessed through further tests, which showed an increase of maximum load. Besides field tests, the bamboo roofs were modelled using finite-element analysis software in order to evaluate the correspondence between experimental and analytical data. The results showed remarkable differences between the actual behaviour of the structures and that obtained from the modelling due to the dimensional unevenness of strips and the imperfect execution of lashed joints, with the latter not always allowed to obtain the ideal hinge bearing condition hypothesised in the analytical model.

\section{Notation}

$E \quad$ elastic modulus of the species tested

$\sigma \quad$ strain of the species tested

\section{Introduction}

\subsection{Manuals}

The manuals by Yona Friedman collected under the title Roofs (Friedman, 1991a, 1991b), which are freely downloadable from the Unesco website, were produced by the Centre for the Communication of Scientific Knowledge, founded by Friedman himself in 1982 thanks to the financial support of the United Nations University, with the aim of popularising scientific knowledge for the benefit of the planet's poor. Roofs is but a fraction of a much broader output, including manuals on various topics essential to survival such as food production and preservation, health, water provision, irrigation, energy, communication, self-organisation and, of course, housing and self-building. The manuals are made up of extremely sketchy drawings coupled with short captions so as to make them understandable to the largest possible number of people.

As it is quite self-obvious, Roofs is focused on the (self-) construction of roofs, which are, in Friedman's view, the most crucial and technically difficult part of a dwelling (Friedman, 1991a: p. 4). In providing instructions on the construction process of different roofs, Friedman was sparing technical details: manuals are open to the interpretation of users, so as to be adapted to local resources - know-how included. Bamboo domes are given a special place in the manuals, not least because Friedman had built several of them in partnership with Eda Schaur in the Museum of Simple Technology, in Madras (Friedman and Schaur, 1987).

Friedman conceived his bamboo domes as composed of two parts: an upper, load-bearing dome, which is the focus of this study, and a lower dome, hanging from the upper one, whose function is to bear a waterproof roofing sheet. Domes are based on square frames with a side of about $3 \mathrm{~m}$, with diagonal braces at the corners so as to create an octagonal drum. Frames are built of whole bamboo culms lashed with rope. Upper domes are instead made of bamboo strips, which are obtained splitting the culms lengthwise: they appear as a series of interweaving arches, with a joint at each intersection. The geometrical shapes of some of them remind us of Guarini's domes.

It is worth remarking that similar constructions, albeit not totally novel, detached themselves from most bamboo architecture for being made of strips instead of whole culms, as is common practice in both vernacular and contemporary buildings. In fact, they seem to compare more appropriately to 
Construction Materials

Volume 175 Issue 2
An investigation of bamboo-strip

constructions built according to

Yona Friedman's manuals

Chiacchiera, Bocco, Ceretto and Ghirardotti
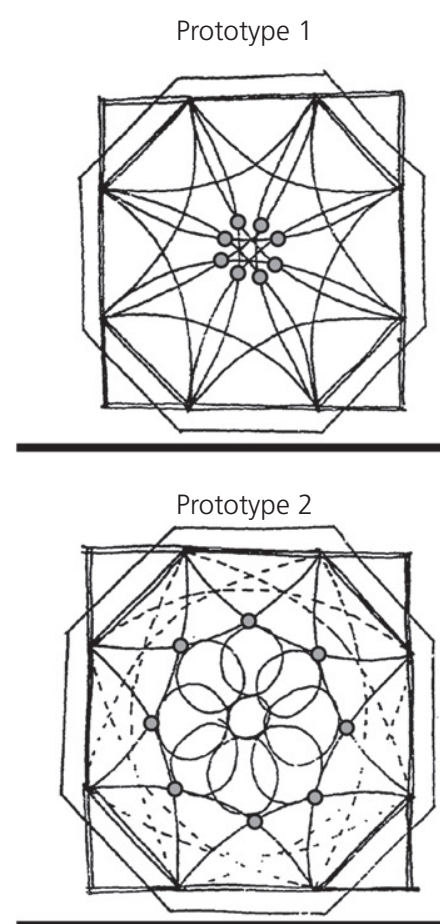

Prototype 3

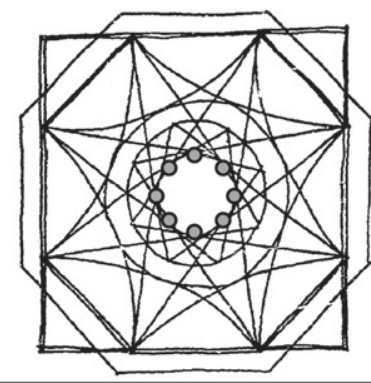

Prototype 4

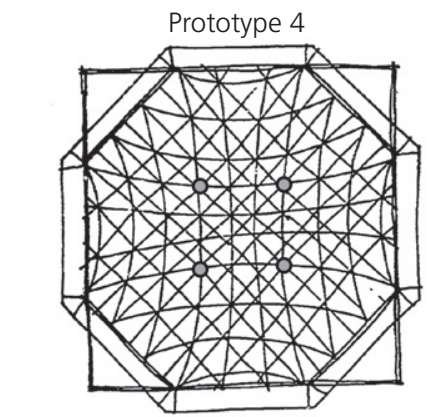

Point of application of load
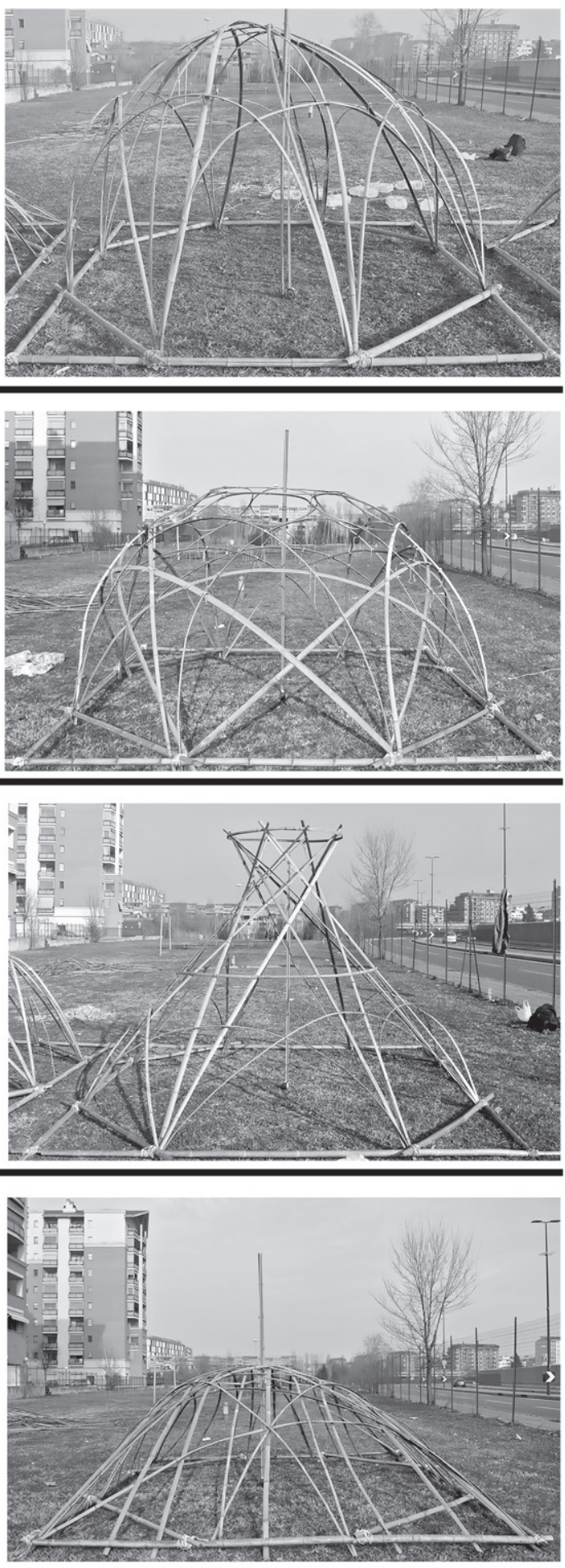

Figure 1. Four prototypes before testing 
basket-making than to framing (see Section 3). The utterly lightweight (and inherently weak) constructions were in fact meant to bear no more than a waterproof membrane and provide some shade.

\subsection{Tested structures}

The purpose of this research study was to investigate the efficacy of Friedman's bamboo domes. The investigation started on four prototypes built by students of architecture during a workshop in May 2015. Clearly, Friedman's manuals were aimed at places where the use of bamboo is widespread and at people with some practical know-how. The students did not possess similar knowledge. Problems encountered with the first prototypes - including weakness of joints between bamboo strips, uneven dimensions of elements and irregular geometry of assemblages - were heavily affected by such lack of experience. Subsequent research tried to solve such flaws and during workshops held in January and June 2016, students were guided by tutors.

Prototype 1 (Figure 1) is a central geometry dome: a hemispherical dome with four rods stemming from each junction of the base frame. Two of them cross at the top of the dome, while the other two diverge laterally, giving rise to segmental arches.

Prototype 2 (Figure 1) is a central geometry dome with four rods stemming from each junction of the base frame. However, here the bamboo arches cross at lower points and the top region of the dome consists of a system of nine rings. Such rings are obtained by curving a bamboo strip and tying together its overlapping ends, obtaining a circle about $70 \mathrm{~cm}$ in diameter

Prototype 3 (Figure 1) is a tapered dome - more precisely, a hyperbolic paraboloid - also with four rods from each junction, two of which are connected to the top ring at diametrically opposed points. The remainder two strips are lower, diverging at the sides, and stiffen the lower part of the dome. Compared with the other three, this prototype is much more slender and has a larger number of intersections between rods and therefore a larger number of joints.

Prototype 4 is an orthogonal grid dome that resembles a gridshell in shape and behaviour (Figure 1).

To sum up, two hemispherical domes $(1,2)$, a paraboloid (3) and a dome with a parabolic cross-section (4) were fabricated. The bamboo used was Phyllostachys viridiglaucescens. Polyester and polypropylene ropes of $3 \mathrm{~mm}$ were tried, obtaining good results in terms of handling and tightening, but (to keep the overall construction as based on natural materials as possible) tests were carriedout on prototypes whose joints had been lashed with a $4 \mathrm{~mm}$ thick hemp rope (critical load $=90 \mathrm{~kg}$ ).

\subsection{The virtual prototypes}

The investigation of virtual prototypes using general structural analysis (GSA), a finite-element analysis software produced by Oasys, allowed an understanding of the behaviour of the bamboo domes in spite of the necessary simplifications that had to be introduced. For instance, perfect standardisation of elements is

Table 1. Mechanical strength of some bamboo species

\begin{tabular}{|c|c|c|c|c|c|c|c|c|c|c|}
\hline \multirow[b]{2}{*}{ Species } & \multirow[b]{2}{*}{$\begin{array}{l}\text { Researcher } \\
\text { (Reference) }\end{array}$} & \multicolumn{2}{|c|}{ Traction } & \multirow[b]{2}{*}{ RH: \% } & \multicolumn{2}{|c|}{ Compression } & \multirow[b]{2}{*}{ RH: \% } & \multicolumn{2}{|c|}{ Bending } & \multirow[b]{2}{*}{ RH: \% } \\
\hline & & $\begin{array}{l}\sigma: \\
\mathrm{N} / \mathrm{mm}^{2}\end{array}$ & $\begin{array}{l}E: \\
\mathrm{N} / \mathrm{mm}^{2}\end{array}$ & & $\begin{array}{c}\sigma: \\
\mathrm{N} / \mathrm{mm}^{2}\end{array}$ & $\begin{array}{c}E: \\
\mathrm{N} / \mathrm{mm}^{2}\end{array}$ & & $\begin{array}{c}\sigma: \\
\mathrm{N} / \mathrm{mm}^{2}\end{array}$ & $\begin{array}{c}E: \\
\mathrm{N} / \mathrm{mm}^{2}\end{array}$ & \\
\hline Bambusa blumeana, Philippines & Janssen (A) & & & & $78 \cdot 0$ & 18800 & 12 & $84 \cdot 0$ & 20500 & 12 \\
\hline B. blumeana, Philippines & Janssen (A) & & & & $80 \cdot 0$ & 18800 & 87 & & & \\
\hline B. blumeana, Philippines & Janssen (A) & & & & $83 \cdot 0$ & 18800 & 4 & & & \\
\hline Bambusa pevaribillis, China & Yuen $(A)$ & & & & $45 \cdot 8$ & 15200 & & & & \\
\hline B. pevaribillis, China & Yu and Chung (A) & & & & $79 \cdot 0$ & 10300 & $<5$ & $80 \cdot 0$ & 22000 & $<5$ \\
\hline B. pevaribillis, China & Yu and Chung (A) & & & & $48 \cdot 0$ & 9300 & $5-20$ & $50 \cdot 0$ & 18500 & $5-20$ \\
\hline B pevaribillis, China & Yu and Chung (A) & & & & $35 \cdot 0$ & 6800 & $>20$ & $37 \cdot 0$ & 16400 & $>20$ \\
\hline Guadua & Puccinelli (B) & 1500 & & & $39 \cdot 0$ & 18800 & & $70 \cdot 0$ & & \\
\hline Guadua, Colombia & Lozano $(C)$ & $61 \cdot 4$ & & 93 & $32 \cdot 9$ & & 87 & $68 \cdot 4$ & & 71 \\
\hline Guadua, Colombia & Lozano (C) & & & & $55 \cdot 0$ & & dry & & & \\
\hline Guadua, Costa Rica & Sotela (A) & & & & $42 \cdot 0$ & 27000 & & & & \\
\hline Oreobambos buchwaldii, Malawi & Ngoma (B) & 1800 & & & $43 \cdot 0$ & 11860 & & 1080 & & \\
\hline Phyllostachys pubescens, China & Yuen $(A)$ & & & & $44 \cdot 6$ & 11300 & & & & \\
\hline P. pubescens, China & Yu and Chung (A) & & & & 1170 & 9400 & $<5$ & $51 \cdot 0$ & 13200 & $<5$ \\
\hline P. pubescens, China & Yu and Chung (A) & & & & $46 \cdot 0$ & 7800 & $5-30$ & $56 \cdot 0$ & 11400 & $5-30$ \\
\hline P. pubescens, China & Yu and Chung (A) & & & & $44 \cdot 0$ & 6400 & $>30$ & $55 \cdot 0$ & 9600 & $>30$ \\
\hline Phyllostachys & Glenn (A) & & & & & & & 1460 & 14800 & \\
\hline
\end{tabular}

References: (A) Chung and Chang (2002); (B) Puccinelli (2007); (C) Trujillo and López (2016)

$\mathrm{RH}$, relative humidity 
impracticable with natural materials, but in the virtual prototypes it was assumed that all bamboo strips had a constant and homogenous section. Moreover, as the effectiveness of hand-made lashes depends on the builders' skill (so that one cannot obtain the same degree of constraint in each joint), all bearings were assumed as hinges. This assumption was due to the fact that it was not possible to estimate the sliding of strips over one another - a phenomenon that actually occurred during field tests.

The mechanical characteristics of bamboo depend on, among other things, the species; in the literature quite different values can be found even for the same species (Table 1).
As characterisation of the material was beyond the scope of this research, which was focused on the building process and structural forms for stress and displacement calculations, an average value for $P$. viridiglaucescens was taken from the literature. For non-linear analyses, it was assumed that $E=11400 \mathrm{MPa}$ (Chung and Chang, 2002: p. 2-21). The moisture content was actually measured: the mean value of samples was $10 \cdot 25 \%$ for those used in January 2016 and $\mathbf{1 0 \cdot 2 7 \%}$ for those used in June 2016. Such values fall in the usually recommended range.

Finally, it immediately became clear that every arc that makes up the structure is subject to compression: given the

Table 2. Displacements and loads in the four prototypes studied during the first series of tests

\begin{tabular}{|c|c|c|c|c|c|c|c|c|c|c|c|c|}
\hline Load: kg & 32 & 40 & 42 & 48 & 64 & 80 & 96 & 100 & 108 & 112 & 128 & 130 \\
\hline \multicolumn{13}{|c|}{ Displacement: mm } \\
\hline Prototype 1 & 40 & 200 & $\mathrm{x}$ & & & & & & & & & \\
\hline Prototype 2 & & & & & 60 & & 150 & & & & 250 & $x$ \\
\hline Prototype 3 & 20 & & & & 60 & & 90 & & 120 & $x$ & & \\
\hline Prototype 4 & 10 & & & 40 & 70 & 100 & 140 & $x$ & & & & \\
\hline
\end{tabular}

$x=$ failure
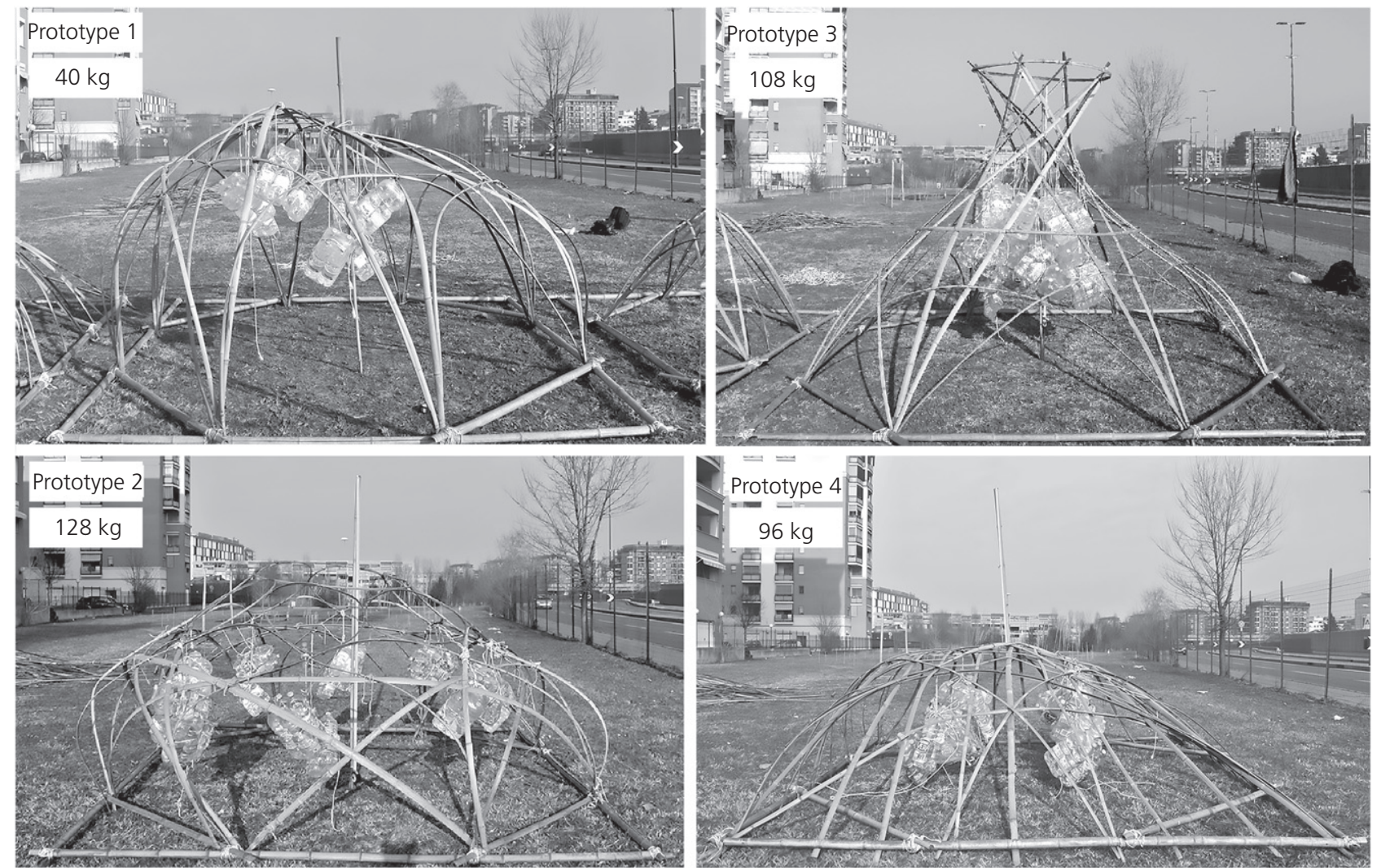

Figure 2. Prototypes under loads of $2-4 \mathrm{~kg}$ less than their respective failure thresholds 
slenderness of the elements, instability problems tend to appear quickly. Therefore, non-linear analysis was necessary in order to take into account the displacement of the load configuration as a result of deformations.

\section{Test results and discussion}

\subsection{Methodology}

The tests consisted of loading the structure progressively, hanging the load from symmetrical points (indicated by dots in Figure 1), although deformation under load was never symmetrical in practice (Figure 2). The addition of load to the structures was continuous over a few hours, therefore allowing no time for the structures to fully creep under load. At each increase in load, the lowering of the structure at the central point was measured.

Two series of tests were carried out on the bamboo domes: the first (see Section 2.2), held in January 2016, concerned the four prototypes described in Section 1.2. In the second series (see Section 2.4), held in June 2016, the improved versions of prototypes 1 and 4 were tested, that had been built in May
2016 according to the results of previous observations (see Section 2.3). In particular, both the joints at the base frame and the connections between the strips were improved; moreover, in prototypes $1 \mathrm{~B}$ and $4 \mathrm{~B}$, each rod was composed of two bamboo strips.

For each prototype, one single sample was built and tested. Therefore, the results of the tests cannot be considered statistically significant in terms of determining the mechanical strength of each structural form; the purpose was rather to compare such structural forms to see which was the stronger and why, and to appreciate if those that appeared to be improvements had actually produced stronger constructions.

\subsection{First series of tests}

Load tests performed in January 2016 was led to the results reported in Table 2 .

Substantial differences in the ultimate strength values were due to several factors: the dimensional differences of the strips (10-40 $\mathrm{mm}$ in width and 3-8 $\mathrm{mm}$ in thickness), together with the imperfect regularity of their arrangement, led to
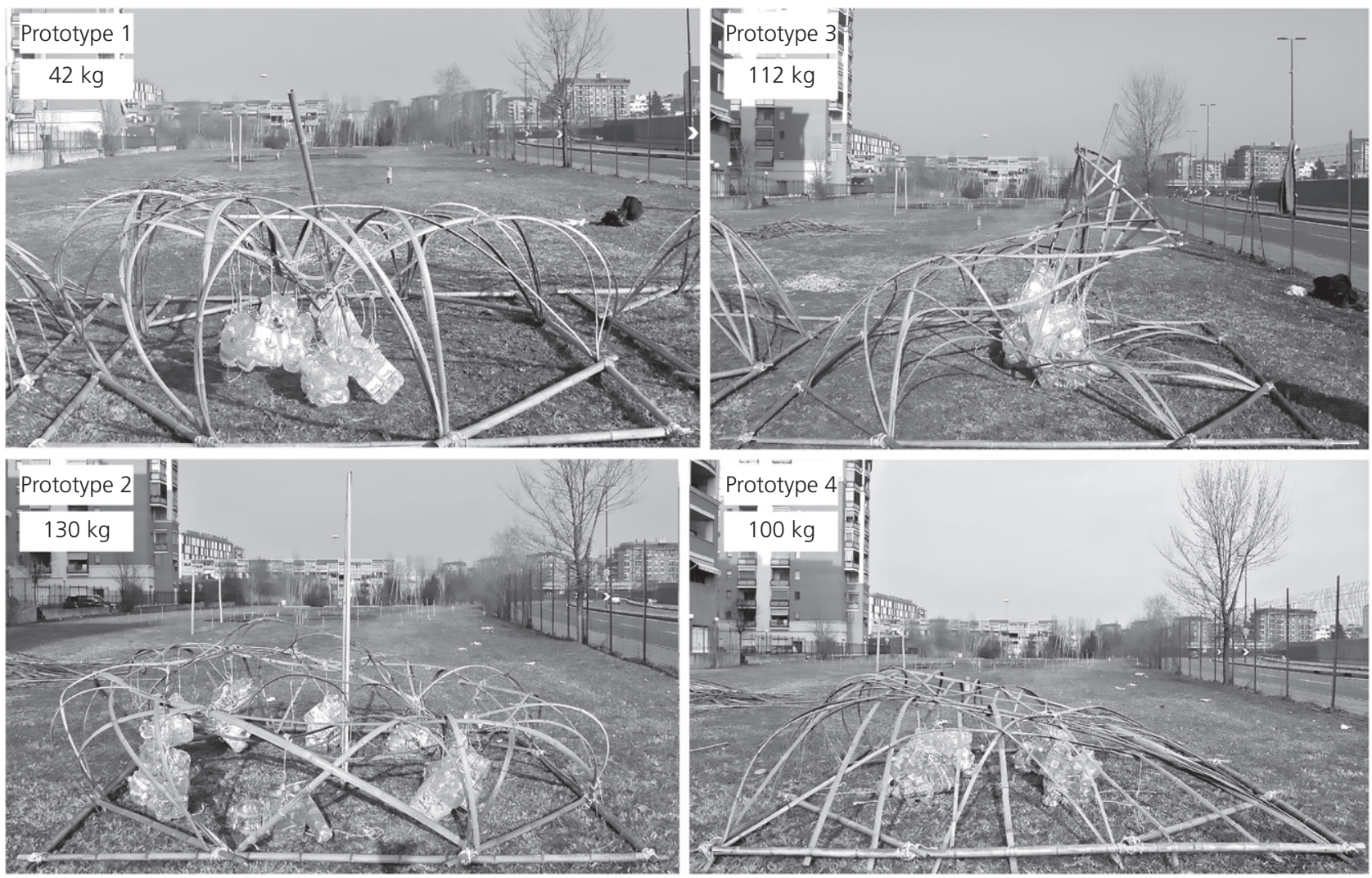

Figure 3. Prototypes at failure 

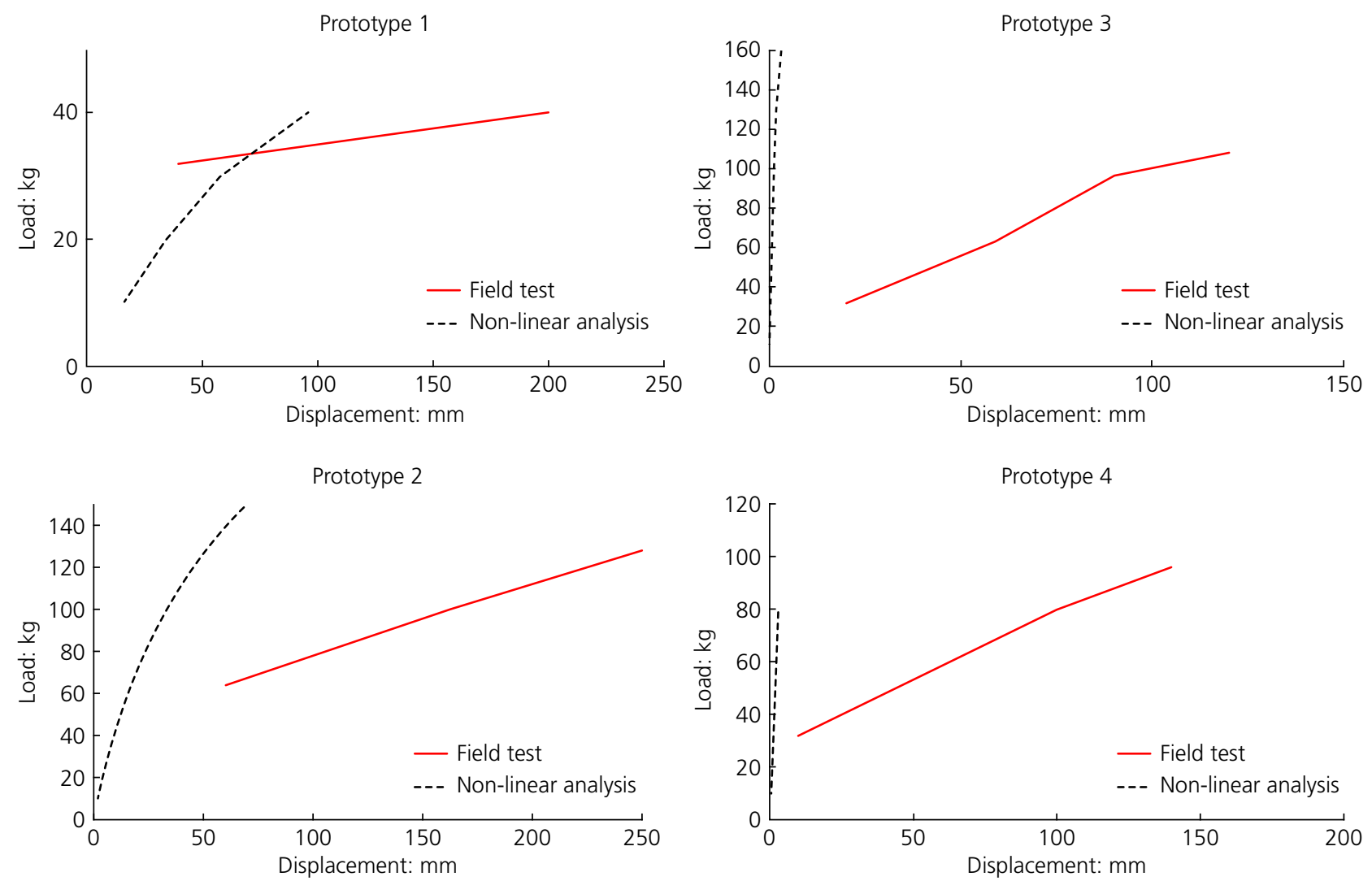

Figure 4. Load-displacement graphs

asymmetrical deformations; the choice of the points of application of loads, moreover, affected the amount of load carried, as can be seen in prototype 1 , where the placement of loads almost at the top of the dome led to the collapse of the structure much earlier than, for example, prototype 2 where the loads were hung from more lateral knots.

Except in prototype 4, the break occurred at the intersection of strips, where the lashing transfers stresses from one element to another. In prototype 4, there was no breakage of the rods: the test had to be interrupted before failure as the weights touched the ground as a consequence of the lowering of the structure, so it was not possible to increase the load further (Figures 2 and 3).

Comparing the results obtained, one can notice an important discrepancy, albeit less evident in prototype 1, where the number of joints was smaller (Figure 4). Possibly, the reason is that while in the virtual prototype it was assumed no rod sliding at overlaps, actually a crossed lashing, although well executed, does not guarantee a perfect hinge - which could have been obtained with a pin in a hole (this detail was rejected so as not to weaken the section at a point where the flexural stresses are highest: bamboo is weak in shear and tensile strength orthogonal to the fibres, so holes are always critical). Ultimately, in the prototypes with a large number of connections, the discrepancies between experimental and analytical results were greater.

\subsection{Improvements to the prototypes}

The first series of tests revealed several critical issues. In a workshop held in May 2016, new versions of two domes (prototypes 1A and 4A) were built by introducing some changes to prototypes 1 and 4 , respectively, to improve their efficiency.

In the first place, the study of knots from basic sailing practice led to a way of lashing that is simple to realise and effective against sliding: repeated at each intersection between rods, it produced a more even distribution of stresses and a homogeneous overall behaviour, avoiding excessive local deformations. 


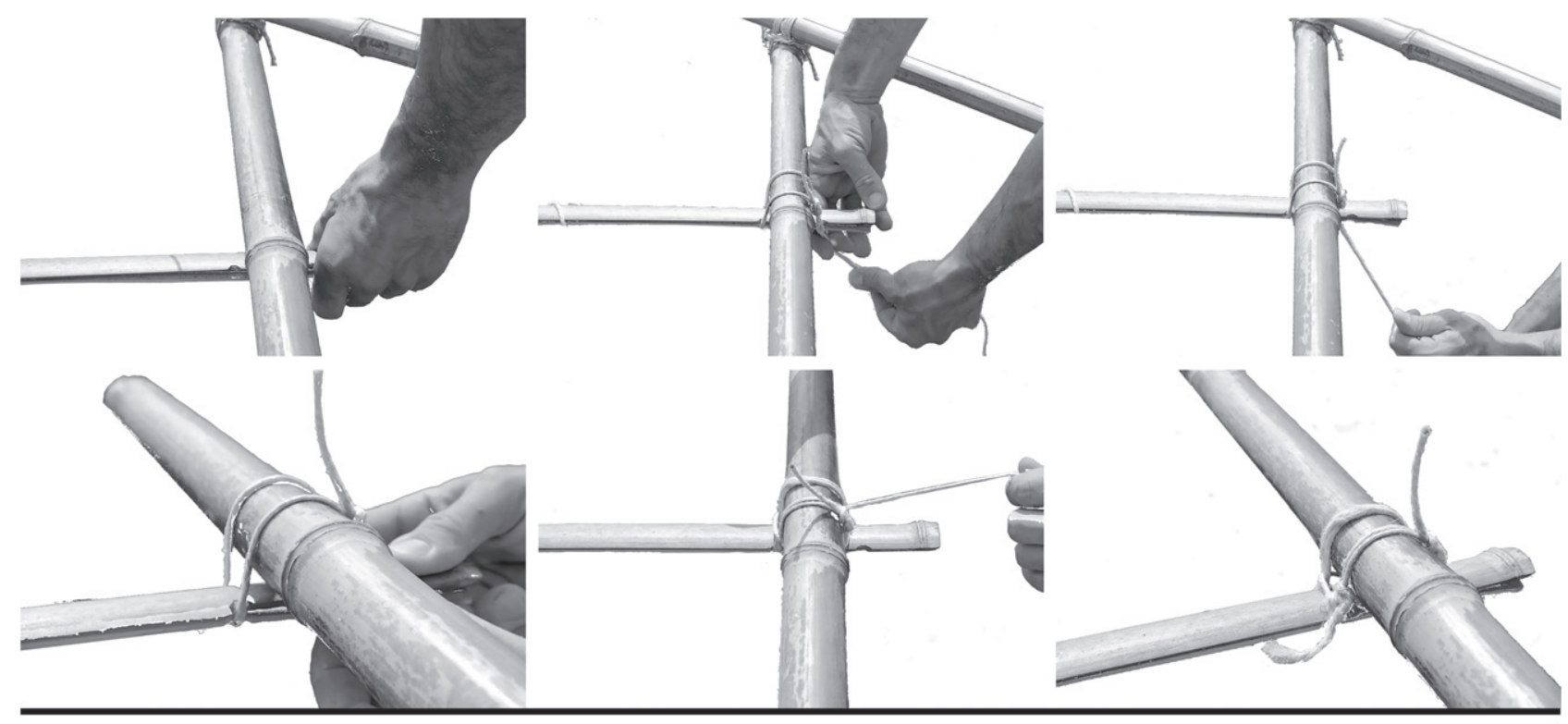

(a)

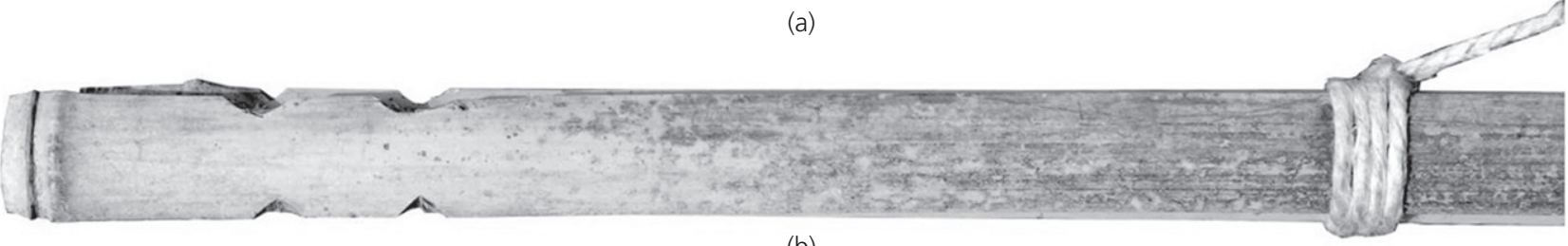

(b)

Figure 5. (a) Sequence showing how one of the dome strips was lashed to a base frame culm. (b) Detail of notches carved on the edges of a bamboo strip

Moreover, at the junctions between the dome and the base frame, where the almost vertical direction of the stresses involves a greater risk of sliding, small notches were cut on the edges of the bamboo strips, in which the rope was passed (Figure 5). The notches were carved by removing the least amount of material possible to minimise weakening of the section. During the tests, no rope slipping or bamboo breakages were observed at these points. This solution is different, but compares with what Toki and Nagai envisaged in their 'bamboo ark' to prevent slippage at joints (Toki and Nagai, 2015).

A further amendment (implemented in prototypes 1B and 4B) was to couple two bamboo strips and therefore double the section of the arched elements. In this case, each rod was obtained by tying together two strips of bamboo at about every $40 \mathrm{~cm}$, so as to create a relatively solid element, comparable to a lamellar rod (Figure 6).

Two central geometry domes and two orthogonal grid domes were built - that is, each of these two models in both the single-strip (respectively, 1A and 4A) and double-strip (respectively, $1 \mathrm{~B}$ and $4 \mathrm{~B}$ ) versions. The construction of such prototypes was carried out in accordance with the same procedures so as to allow comparability of the results. The dimensional homogeneity of sections was also checked more carefully than in the previous workshop, so as to minimise weak points.

\subsection{Second series of tests}

In the second series of tests, loads were progressively applied on a $100 \times 100 \times 2 \mathrm{~cm}$ wooden board. This expedient simplified the operation of increasing the load, obtaining at the same time an even distribution at all the points of application.

Prototype 1A showed a better response to load compared with prototype 1 . In addition to having considerably smaller displacements, it collapsed when charged with a load over three times larger $(130 \mathrm{~kg})$.

The results of prototype 1B were even better and almost directly proportional to those of prototype 1A: the displacements were about one-half and the ultimate load was slightly more than double $(270 \mathrm{~kg})$. Unlike the first series of tests, 


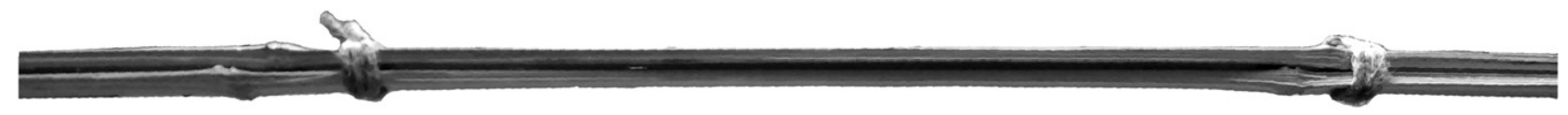

Figure 6. 'Lamellar rod' created coupling two bamboo strips (side view)


Figure 7. Comparison of loading and deformations in prototypes $1 \mathrm{~A}$ and $4 \mathrm{~A}$ with their respective 'enhanced' versions, $1 \mathrm{~B}$ and $4 \mathrm{~B}$

there were no transverse cracks in the rods, but strong torsions and longitudinal splits, contained by the ties.

The displacements recorded for prototype $4 \mathrm{~A}$ were close to those of prototype 4 until a load of $100 \mathrm{~kg}$. At this point, prototype 4 had collapsed, while 4A reached a load of $156 \mathrm{~kg}$. Here, it is the interlacement which kept the rods together when they displaced vertically: the contribution of lashings was less essential. For this reason, enhancing the ties was less influential on the strength of the structure compared with prototype 1A. The structure was symmetrically deformed, demonstrating the good load distribution of the grid arrangement.
Prototype 4B showed significantly smaller displacements than $4 \mathrm{~A}$; the difference in behaviour gradually increased with the load (Figure 7) (see test results in Table 3).

It may be interesting to compare the weight (dead load) of the structures built in the second phase and their ultimate loads.

- Prototype 1A had a weight of $18 \cdot 7 \mathrm{~kg}(11 \cdot 2 \mathrm{~kg}$ of strips, $7 \cdot 5 \mathrm{~kg}$ of whole culms) and supported $130 \mathrm{~kg}$; $1 \mathrm{~B}$ weighed $25.9 \mathrm{~kg}(18.4 \mathrm{~kg}$ of strips, $7.5 \mathrm{~kg}$ of culms) and supported $285 \mathrm{~kg}$. 
Table 3. Displacements and loads in the four prototypes studied during the second series of tests

\begin{tabular}{|c|c|c|c|c|c|c|c|c|c|c|c|c|c|c|c|c|c|}
\hline Load: kg & 30 & 50 & 70 & 90 & 110 & 130 & 150 & 170 & 190 & 210 & 230 & 250 & 270 & 290 & 310 & 330 & 350 \\
\hline \multicolumn{18}{|c|}{ Displacement: mm } \\
\hline Prototype $1 \mathrm{~A}$ & 25 & 55 & 88 & 115 & 140 & 195 & & & & & & & & & & & \\
\hline Prototype 1B & 18 & 27 & 48 & 67 & 80 & 88 & 95 & 116 & 122 & 135 & 155 & 172 & 236 & & & & \\
\hline Prototype 4A & 25 & 50 & 75 & 105 & 145 & 173 & 230 & & & & & & & & & & \\
\hline Prototype 4B & & 11 & 66 & 85 & 90 & 118 & 132 & 147 & 175 & 188 & 210 & 228 & 247 & 285 & 333 & 485 & 530 \\
\hline
\end{tabular}

- Prototype $4 \mathrm{~A}$ weighed $20 \cdot 2 \mathrm{~kg}(12 \cdot 8 \mathrm{~kg}$ of strips, $7 \cdot 4 \mathrm{~kg}$ of culms) and supported $150 \mathrm{~kg}$; 4B weighed $28.8 \mathrm{~kg}(21.4 \mathrm{~kg}$ of strips, $7 \cdot 4 \mathrm{~kg}$ of culms) and supported $348 \mathrm{~kg}$.

Therefore, the ratios between dead load and ultimate loads were, respectively, $1: 7,1: 11,1: 7$ and $1: 12$.

\section{Conclusions and future work}

The difference in mechanical performance of the analysed domes is quite patent. The orthogonal grid dome (prototypes 4, 4A, 4B) was the most efficient. Although this model is composed of a greater number of rods, the main advantage is that the interweaving of strips implies much more friction and creates a much stiffer assembly than simple lashed joints of the reciprocally tangent elements, as in the other dome models. Another advantage is the fact that the individual arches lay in vertical planes, with instability problems outside of the plane of the arches reduced.

It was deduced that it was not by accident that a number of researchers have been trying to transpose the 'basket weaving principle' into civil engineering, given the inherent lightness and strength of this arrangement of very thin and possibly very low-cost vegetal-origin elements, which can be assembled even with a basic crafting skill. To name but a few attempts, see the bamboo grid-shell experimentations carried out at Frei Otto's IL (in particular Fritz et al., 1985; Gaß et al., 1985; Schaur, 1985) and, more recently, the earthquake-resistant 'woven timber system' by Shankar (2016) and also, to some extent, the 'bug dome' installation in Shenzhen by WEAK! architects (Beckham, 2009; Lyons, 2009).

A continuation of this work could concern the study of bamboo lamellar arches, focusing mainly on the shape of the arch and on the joining techniques between the strips (or lamellae). Similar elements have already been built in the past by Marcelo Villegas (Minke, 2012: p. 54) and by Gernot Minke at the Building Research Laboratory of the University of Kassel (Minke, 1985, 1999: p. 36, 2012: pp. 55 and 61). Unfortunately, it seems there is no scientific literature describing the performances of these experimental prototypes.

\section{Acknowledgements}

This research study was conducted by Paolo Chiacchiera and Davide Ghirardotti as part of a master's thesis in architecture at the Politecnico di Torino, under the supervision of Professors Andrea Bocco and Walter Ceretto. The material used was obtained from a bamboo grove in Piscina (TO), courtesy of Walter Montiglio and with the help of Walter himself and Roberto Pichetto, promoters of the bamboo supply chain in Piedmont. The structures were built and tested at the Parco d'Arte Vivente in Turin (PAV) during two workshops held in November 2015 and May 2016. For the analysis of the virtual prototype with GSA software, considerable support was provided by Davide Bigaran. GSA software allows the calculation of stresses and displacements starting from a three-dimensional geometric model of the structure, setting the mechanical properties of the materials and the load configuration.

\section{REFERENCES}

Beckham R (2009) WEAK! Architects at Shenzhen Hong Kong Biennale. Designboom. Seehttps://www.designboom.com/ architecture/weak-architects-at-shenzhen-hong-kong-biennale/ (accessed 10/12/2009).

Chung KF and Chang SL (2002) Design of Bamboo Scaffolds. INBAR \& The Hong Kong Polytechnic University, Beijing, People's Republic of China, Technical report No. 23.

Friedman Y (1991a) Roofs Part 1. Unesco, Paris, France. See http://unesdoc.unesco.org/images/0008/000876/087695eb.pdf (accessed 22/03/2019).

Friedman Y (1991b) Roofs Part 2. Unesco, Paris, France. See http://unesdoc.unesco.org/images/0009/000908/090863eb.pdf (accessed 22/03/2019).

Friedman Y and Schaur E (1987) Museum of simple technology - a tool for development. Space+Society 40: 86-93.

Fritz J, Gaß S, Greiner S, Reiner R and Voigt H (1985) Using vegetal rods for arches, vaults, domes and shells. In IL31 Bamboo (Gaß S, Drüsedau H and Hennicke J (eds)). Institut für leichte Flächentragwerke, Stuttgart, Germany, pp. 304-319.

Gaß S, Drüsedau H and Hennicke J (eds) (1985) IL31 Bamboo. Institut für leichte Flächentragwerke, Stuttgart, Germany. Lyons N (2009) Bug Dome by WEAK! Dezeen. See https://www. dezeen.com/2009/12/14/bug-dome-by-weak/ (accessed 14/12/2009).

Minke G (1985) Bamboo arch and grid structures. New opportunities for extremely light-weight roof structures made from bamboo. In IL31 Bamboo (Gaß S, Drüsedau H and Hennicke J (eds)). Institut für leichte Flächentragwerke, Stuttgart, Germany, pp. $342-347$. 
Minke G (1999) Experimentelles Bauen. Ein Werkbericht zum 20-jährigen Bestehen des Forschungslabors für Experimentelles Bauen. Ökobuch, Staufen bei Freiburg, Germany (in German). Minke G (2012) Building with Bamboo. Design and Technology of a Sustainable Architecture. Birkhäuser, Basel, Switzerland. Puccinelli N (2007) Coperture Sismoresistenti in Bambù: Prove Sperimentali ed Aspetti Progettuali per Edifici a basso Costo. Master's thesis, Università di Pisa, Pisa, Italy (in Italian).

Schaur E (1985) Some characteristic forms of bamboo structures. In IL31 Bamboo (Gaß S, Drüsedau H and Hennicke J (eds)). Institut für leichte Flächentragwerke, Stuttgart, Germany, pp. 320-337.
Shankar S (2016) Revitalizing traditional knowledge and bio-cultural heritage in North-East India. See http://www.sanjeevshankar. $\mathrm{com} / \mathrm{pdf} /$ Revitalizing-traditional-knowledge-and-bio-culturalheritage-Sanjeev-Shankar-2016.pdf (accessed 22/03/2019).

Toki H and Nagai T (2015) Spatial structure using bamboo as structural material: design and construction of emergency temporary building made of bamboo material (part 1). AIJ Journal of Technology and Design 21(49): 1007-1012.

Trujillo D and López LF (2016) Bamboo material characterization. In Nonconventional and Vernacular Construction Materials (Harries KA and Sharma B (eds)). Woodhead Publishing, Duxford, UK, pp. 365-392.

\section{How can you contribute?}

To discuss this paper, please email up to 500 words to the editor at journals@ice.org.uk. Your contribution will be forwarded to the author(s) for a reply and, if considered appropriate by the editorial board, it will be published as discussion in a future issue of the journal.

Proceedings journals rely entirely on contributions from the civil engineering profession (and allied disciplines).

Information about how to submit your paper online is available at www.icevirtuallibrary.com/page/authors, where you will also find detailed author guidelines. 